\title{
Robust satellite techniques (RST) for the thermal monitoring of earthquake prone areas: the case of Umbria-Marche October, 1997 seismic events
}

\author{
Carolina Aliano $\left({ }^{1}\right)$, Rosita Corrado $\left({ }^{1}\right)$, Carolina Filizzola $\left({ }^{2}\right)$, Nicola Pergola $\left({ }^{1}\right)\left({ }^{2}\right)$, Valerio Tramutoli $\left({ }^{1}\right)\left({ }^{2}\right)$ \\ $\left.{ }^{(}\right)$Dipartimento di Ingegneria e Fisica dell'Ambiente, Università degli Studi della Basilicata, Potenza, Italy

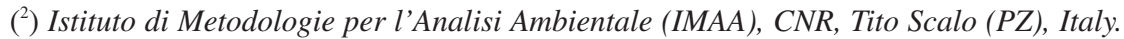

\begin{abstract}
Several authors claim a space-time correlation between increases in Earth's emitted Thermal Infra-Red (TIR) radiation and earthquake occurrence. The main problems of such studies regard data analysis and interpretation, which are often done without a validation/confutation control. In this context, a robust data analysis technique (RST, i.e. Robust Satellite Techniques) is proposed which permits a statistically based definition of TIR «anomaly» and uses a validation/confutation approach. This technique was already applied to satellite TIR surveys in seismic regions for about twenty earthquakes that occurred in the world. In this work RST is applied for the first time to a time sequence of seismic events. Nine years of Meteosat TIR observations have been analyzed to characterize the unperturbed TIR signal behaviour at specific observation times and locations. The main seismic events of the October 1997 Umbria-Marche sequence have been considered for validation, and relatively unperturbed periods (no earthquakes with $\mathrm{Mb} \geq 4$ ) were taken for confutation purposes. Positive time-space persistent TIR anomalies were observed during seismic periods, generally overlapping the principal tectonic lineaments of the region and sometimes focusing on the vicinity of the epicentre. No similar (in terms of relative intensity and space-time persistence) TIR anomalies were detected during seismically unperturbed periods.
\end{abstract}

Key words earthquake - satellite-thermal-infraredMeteosat - Umbria-Marche - RST

\section{Introduction}

In recent decades, a growing number of studies (Gorny et al., 1988; Ouzounov et al., 2006; Ouzounov et al., 2007; Pulinets et al., 2006a; Qiang et al., 1991, Qiang et al., 1992, Qiang et al., 1997; Saraf and Choudhury, 2005a, Saraf and Choudhury, 2005b; Tronin,

Mailing address: Dr. Carolina Aliano, Dipartimento di Ingegneria e Fisica dell'Ambiente, Università degli Studi della Basilicata, Via dell'Ateneo Lucano, 85100 Potenza, Italy; e-mail: carolaliano@gmail.com
1996; Tronin, 2000; Tronin et al., 2002) based on Thermal Infrared (TIR) $\left({ }^{1}\right)$ meteorological satellite data have reported large scale (up to hundreds $\mathrm{km}$ ) positive variations (from 3 to 6 $\mathrm{K}$ ) of Earth's TIR emission during a time (from weeks to days) before earthquake occurrence, suggesting a possible relation between «anomalous» space-time fluctuations of such TIR signal and earthquake occurrence.

Some of these papers have been greeted with some scepticism by the scientific community mainly due to the poor methods used for

( $\left.{ }^{1}\right)$ Earth's thermally emitted radiation measured from satellite in the Thermal Infrared $(8-14 \mu \mathrm{m})$ spectral range is usually referred to as TIR signal and given in units of Brightness Temperature (BT) measured in Kelvin degrees. 
the analysis of satellite TIR images (e.g. Tramutoli et al., 2001) and result interpretation (e.g. Geller, 1997). In fact, the main problems in the above-mentioned studies were the lack of a rigorous definition of anomalous TIR signal fluctuations, the absence of a convincing testing step based on a validation/confutation approach and the scarce attention paid to the possibility that causes (e.g. meteorological) other than seismic activity could be responsible for the observed TIR variations (Tramutoli et al., 2005).

Several authors interpreted such thermal signals as pre-seismic, invoking different natural processes to explain the origin of enhanced TIR emission, among them: (a) rising fluids that would lead to the emanation of warm gases (Salman et al., 1992; Gorny et al., 1988); (b) rising well water levels and $\mathrm{CO} 2$ spreading laterally causing a «local greenhouse» effect (Qiang et al.,1991; Tronin et al., 2002; Tramutoli et al., 2005); (c) activating positive-hole pairs during rock deformation (Freund, 2002); (d) Air ionization by radon and latent heat change due to change of air humidity (Pulinets et al., 2006b).

In this context, a Robust Satellite dataanalysis Technique (RST) was developed (Tramutoli, 1998; Tramutoli, 2005; Tramutoli, 2007) which offers a statistically founded definition of TIR anomaly and improved capability to identify anomalous space-time TIR signal transients even in very variable observational (satellite view angle, land topography and coverage, etc.) and natural (e.g. meteorological) conditions. RST is based on a preliminary multi-temporal analysis performed on a homogeneous historical series of satellite records devoted to characterizing the measured signal in terms of its main value and variation range.

RST possible application to satellite TIR surveys in seismically active regions has already been successfully tested in different cases of earthquakes of magnitude higher than 5.5: Irpinia, $23^{\text {rd }}$ November 1980 (Di Bello et al., 2004; Tramutoli et al., 2001); Athens, $7^{\text {th }}$ September 1999 (Filizzola et al., 2004); Izmit: 17th August 1999 (Aliano et al., 2007; Tramutoli et al., 2005); Gujarat, 26 ${ }^{\text {th }}$ January 2001(Genzano et al., 2007), Boumerdes/Thenia, $21^{\text {st }}$ May 2003 (Aliano et al., 2007); Hector Mine $16^{\text {th }}$ October 1999 (Aliano et al., 2007). Ms=7,4 as well as in the cases of 9 medium-low magnitude $(4<\mathrm{Mb}<5.5)$ events in Greece and Turkey (Aliano et al., 2007; Corrado et al., 2005; Di Bello et al., 2004; Filizzola et al., 2004; Tramutoli et al., 2001; Tramutoli, 2005). The approach has been implemented by using a validation/confutation approach, devoted to verifing the presence/absence of anomalous spacetime TIR transients in the presence/absence of seismic activity. In some of these test cases, to identify anomalous TIR patterns, a specific index, RETIRA (Robust Estimator of TIR Anomalies, Filizzola et al., 2004; Tramutoli, 2005), was computed on the image at hand as in eq. (1.1):

where:

$$
\otimes_{\Delta T}(\boldsymbol{r}, t)=\frac{\Delta T(r, t)-\mu_{\Delta T}(\boldsymbol{r})}{\sigma_{\Delta T}(\boldsymbol{r})}
$$

$\boldsymbol{r} \equiv(\mathrm{x}, \mathrm{y})$ represents location coordinates of the pixel center on a satellite image;

$t$ is the time of image acquisition with $\mathrm{t} \in \tau$, where $\tau$ defines the homogeneous domain of satellite imagery collected in the same time-slot of the day and period of the year;

$\Delta \mathrm{T}(\boldsymbol{r}, t)$ is the value of the difference between the punctual value of brightness temperature $\mathrm{T}(\boldsymbol{r}, t)$ at the location $\mathrm{r} \equiv(\mathrm{x}, \mathrm{y})$ and at the acquisition time $\mathrm{t}$ and its spatial average $\mathrm{T}(t)$ (i.e. $\Delta \mathrm{T}(\boldsymbol{r}, t)=\mathrm{T}(\boldsymbol{r}, t)-\mathrm{T}(t))$ computed on the investigated area considering only cloud-free locations, all belonging to the same, land or sea, class (i.e. considering only sea pixels if $\boldsymbol{r}$ is located on the sea and only land pixels if it is located on the land);

$\mu_{\Delta \mathrm{T}}(\boldsymbol{r})$ time average value of $\Delta \mathrm{T}(\boldsymbol{r}, t)$ at the location $\boldsymbol{r} \equiv(\mathrm{x}, \mathrm{y})$ computed on cloud free record belonging the selected data set $(t \in \tau)$;

$\sigma_{\Delta \mathrm{T}}(\boldsymbol{r})$ standard deviation of $\Delta \mathrm{T}(\boldsymbol{r}, t)$ at the location $\boldsymbol{r} \equiv(\mathrm{x}, \mathrm{y})$ computed on cloud free record belonging the selected data set $(t \in \tau)$.

By construction, the RETIRA index turns out to be a useful tool for a robust identification of TIR anomalies and allows us to estimate them in terms of the Signal-to-Noise $(\mathrm{S} / \mathrm{N})$ ratio. In fact, the local excess $\Delta \mathrm{T}(\boldsymbol{r}, t)-\mu_{\Delta \mathrm{T}}(\boldsymbol{r})$, which represents the Signal (S) to be investigated for its possible relation with seismic activity, is evaluated by comparison with the correspon- 


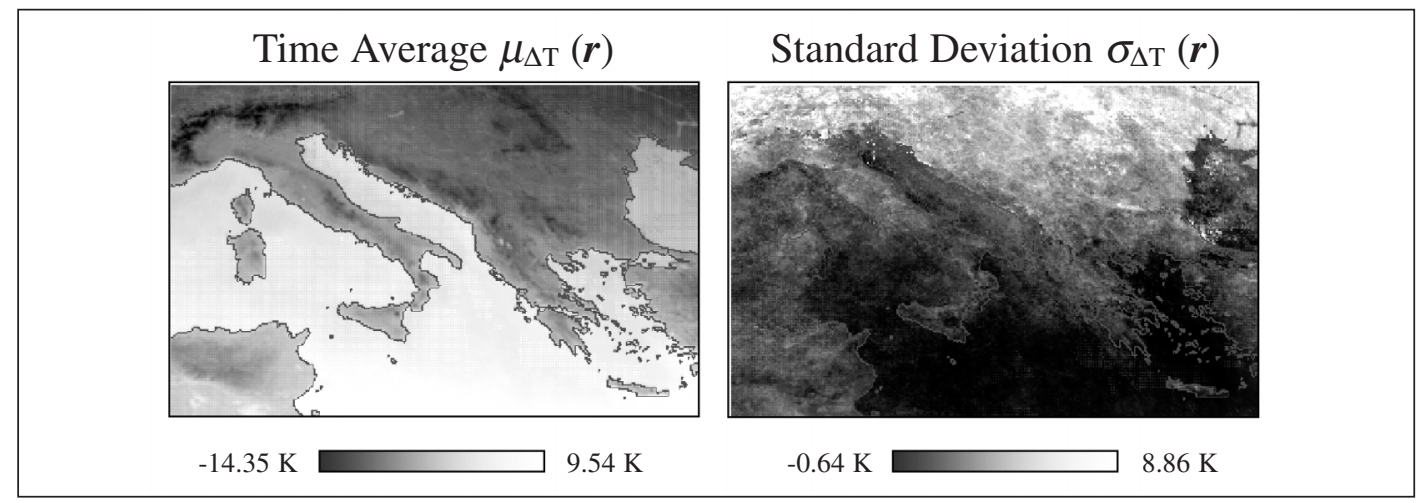

Fig. 1. Reference field (time average $\mu_{\Delta \mathrm{T}}$ and standard deviation $\sigma_{\Delta \mathrm{T}}$ ) on the study area for the month of October at 24:00 GMT computed on Meteosat TIR records over the years 1992-2000 (see text).

ding observational/natural Noise $(\mathrm{N})$ represented by $\sigma_{\Delta \mathrm{T}}(\boldsymbol{r})$. It is important to note that $\sigma_{\mathrm{V}}(\boldsymbol{r})$ includes all (natural and observational, known and unknown) sources of the overall (local) variability of $\mathrm{S}$ as historically observed at the same site in similar observational conditions (platform, time of day, month, etc). This way, the relative importance of the measured TIR signal (or the intensity of anomalous TIR transients) can naturally be evaluated in terms of $\mathrm{S} / \mathrm{N}$ ratio by the RETIRA index.

As a result, the RETIRA index is intrinsically resistant to false alarms (robustness) and, in addition, may assure a complete exportability to different geographical areas and a free choice of sensors to be used.

As a matter of fact, the robustness and potentials RST approach were widely assessed in monitoring of areas with a very different extension (from rather limited regions like Italian peninsula to very wide areas like Indian Subcontinent), highly variable morphology and very different geo-tectonic settings (compressive, transcurrent and distensive fault zones), considering different kinds of earthquakes for localization (both boundary plate and intraplate events) and magnitude (from 4.0 to 7.9). Furthermore, RST intrinsic exportability on different satellite instrumental packages was evaluated on the basis of several years of
NOAA/AVHRR $\left({ }^{2}\right)$, Meteosat and $\operatorname{GOES}\left({ }^{3}\right)$ observations and allowed us to verify, for example, that the best performances (in terms of $\mathrm{S} / \mathrm{N}$ ) of RST can be found moving from polar to geo-stationary satellites (Filizzola et al., 2004).

In this work, RST is applied to the main events that occurred in October, 1997 during the Umbria-Marche (Apennines, Central Italy) seismic sequence. We chose to study - for the first time - a unique sequence of seismic events generated in the same area (rather than different spatially scattered) to better understand the relationship between TIR anomaly intensity and earthquake magnitude, the geologic conditions being the same. Umbria-Marche region was also chosen a as test case because the Central Apennines are one of most degassing areas in Italy, and enhanced gas emission is one of the mechanisms proposed to explain TIR anomalies in some relation with seismic activity (e.g. Tronin, 2000).

( $\left.{ }^{2}\right)$ Advanced Very High Resolution Radiometer onboard NOAA (National Oceanographic and Atmospheric Administration) platforms.

$\left({ }^{3}\right)$ Geostationary Operational Environment Satellites operated by NOAA. 


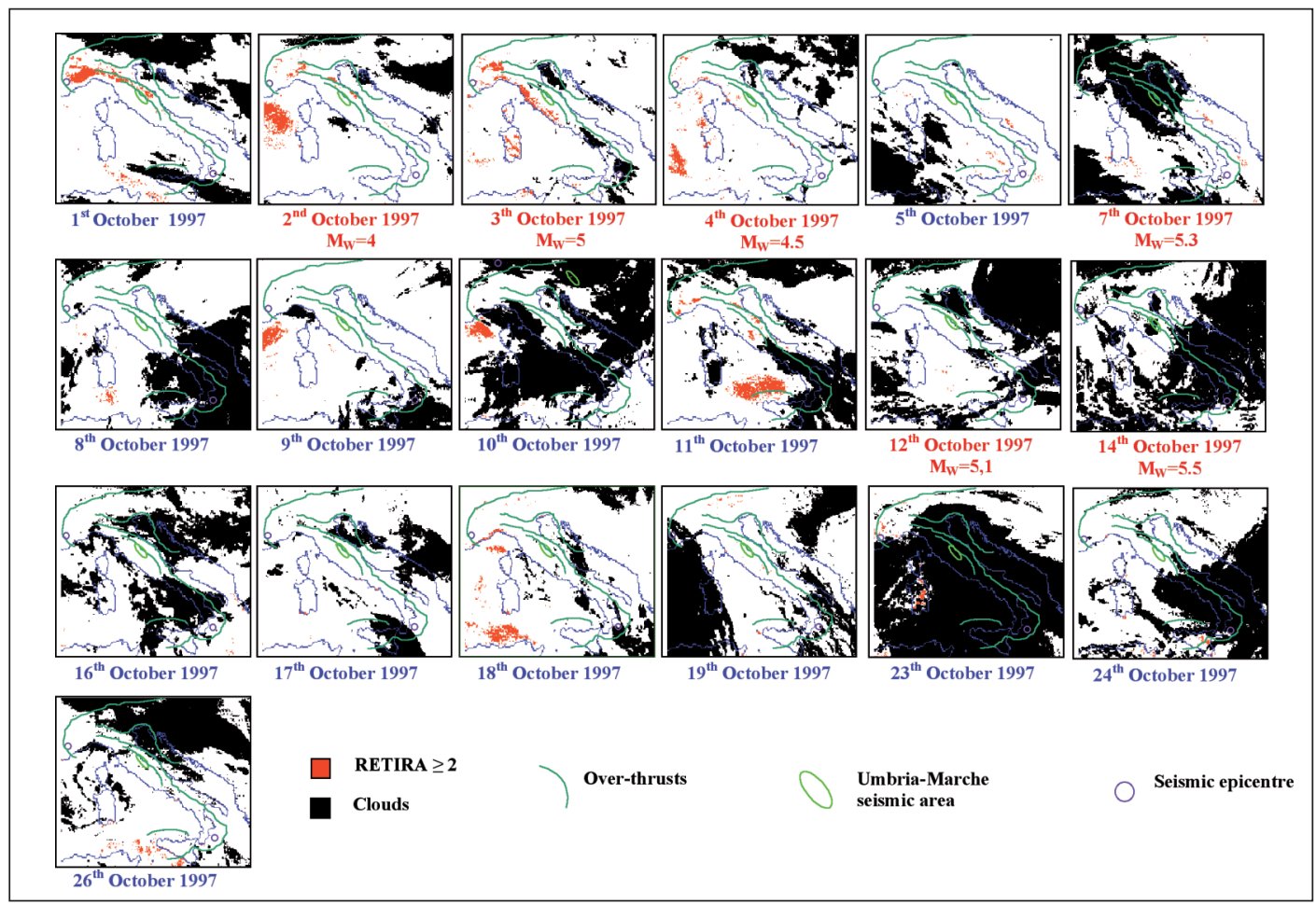

Fig. 2. Validation: results of the RETIRA index computation on the investigated area (see text). Overcast scenes and images which are affected by navigation errors are not shown. The datas of Umbria-Marche earthquakes, together with their magnitude, are reported in red.

\section{The case of October 1997 Umbria-Marche earthquakes}

We considered the earthquakes that occurred during the month of October 1997 (the strongest event of the whole 1997 seismic sequence occurred on $14^{\text {th }}$ October 1997 , with a $\mathrm{M}_{\mathrm{w}}=5.6$ ) as test cases for the validation phase, and we took less seismically perturbed periods (no earthquakes with $\mathrm{M}_{\mathrm{b}} \geq 4$, in the same region and in the same month but in different years) for confutation purposes.

RST implementation starts with the characterization of the unperturbed TIR signal expected at each specific location in observational conditions as similar as possible that one of the image under analysis. To this aim, we built a homo- geneous data-set, including all cloud-free $\left({ }^{4}\right)$ Meteosat TIR images acquired from 1992 to 2000 (nine years of satellite observations!) night-time $\left({ }^{5}\right)$ in the same hour of the day (24:00 GMT) during the month of October. Reference fields $\left(\mu_{\Delta \mathrm{T}}(\boldsymbol{r})\right.$ and $\left.\sigma_{\Delta \mathrm{T}}(\boldsymbol{r})\right)$, computed for this month and study area, are shown in fig. 1.

Results of the RETIRA index computation

$\left({ }^{4}\right)$ Cloud-detection has been wherever performed by using the One-channel Cloud-detection Approach (OCA) described in Cuomo et al., 2004.

$\left.{ }^{5}\right)$ We use night-time images to reduce major signal fluctuations due to local solar exposition, which is very variable in the space-time domain. 


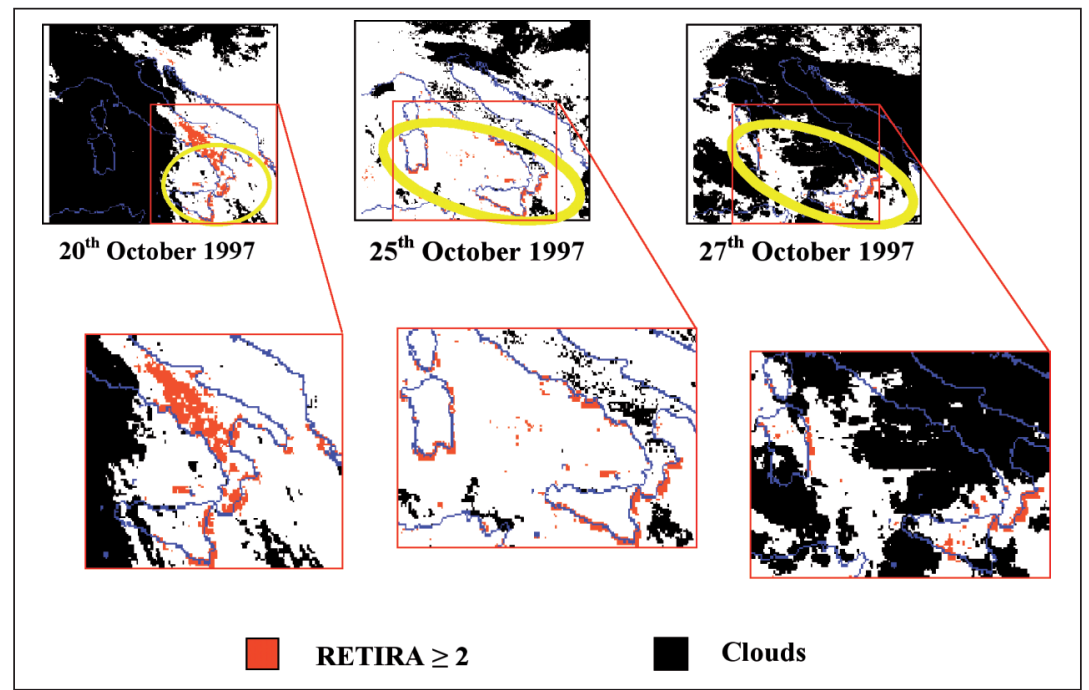

Fig. 3. Validation: images we found affected by navigation errors (see text). The effects are visible near the inshore lines (yellow circles); on the bottom, a closer view of the coastal areas.

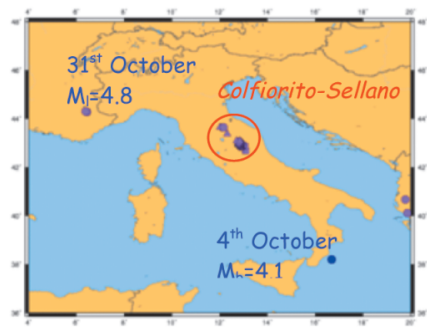

a)

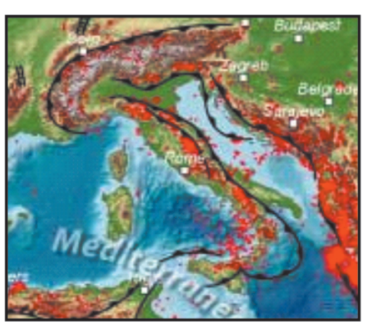

Earthquakes with
$\mathrm{M}>4(1980-2004)$

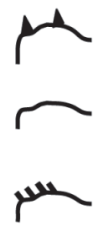

Thrust fault

Strike-slip fault

Normal fault

b)

Fig. 4. a) October 1997 event map (source IRIS, http://www.iris.washington.edu); b) tectonic and seismicity map of the Mediterranean West (source National Earthquake Information Centre - NEIC; http://neic.usgs.gov/neis/epic/epic_global.html)

on the investigated area are shown in the next sections, where space-time TIR signal transients, both in the presence (validation) and absence of (confutation) seismic events, will be analysed looking for possible space-time relationships with earthquake occurrence. All images refer to Meteosat TIR observations collected at 24:00 GMT.

\section{Validation}

Figure 2 shows the results of the RETIRA index $\left(\otimes_{\Delta \mathrm{T}}(\boldsymbol{r}, t)\right)$ computation for the October 1997. Pixels with $\otimes_{\Delta \mathrm{T}}(\boldsymbol{r}, t) \geq 2$ (i.e. $\Delta \mathrm{T}(\boldsymbol{r}, t)$ $\mu_{\Delta \mathrm{T}}(\boldsymbol{r})$ excess greater than $\left.2 \sigma_{\Delta \mathrm{T}}(\boldsymbol{r})\right)$ are depicted in red and hereafter, only for sake of simplicity, we will refer to them as «TIR anomalies». 


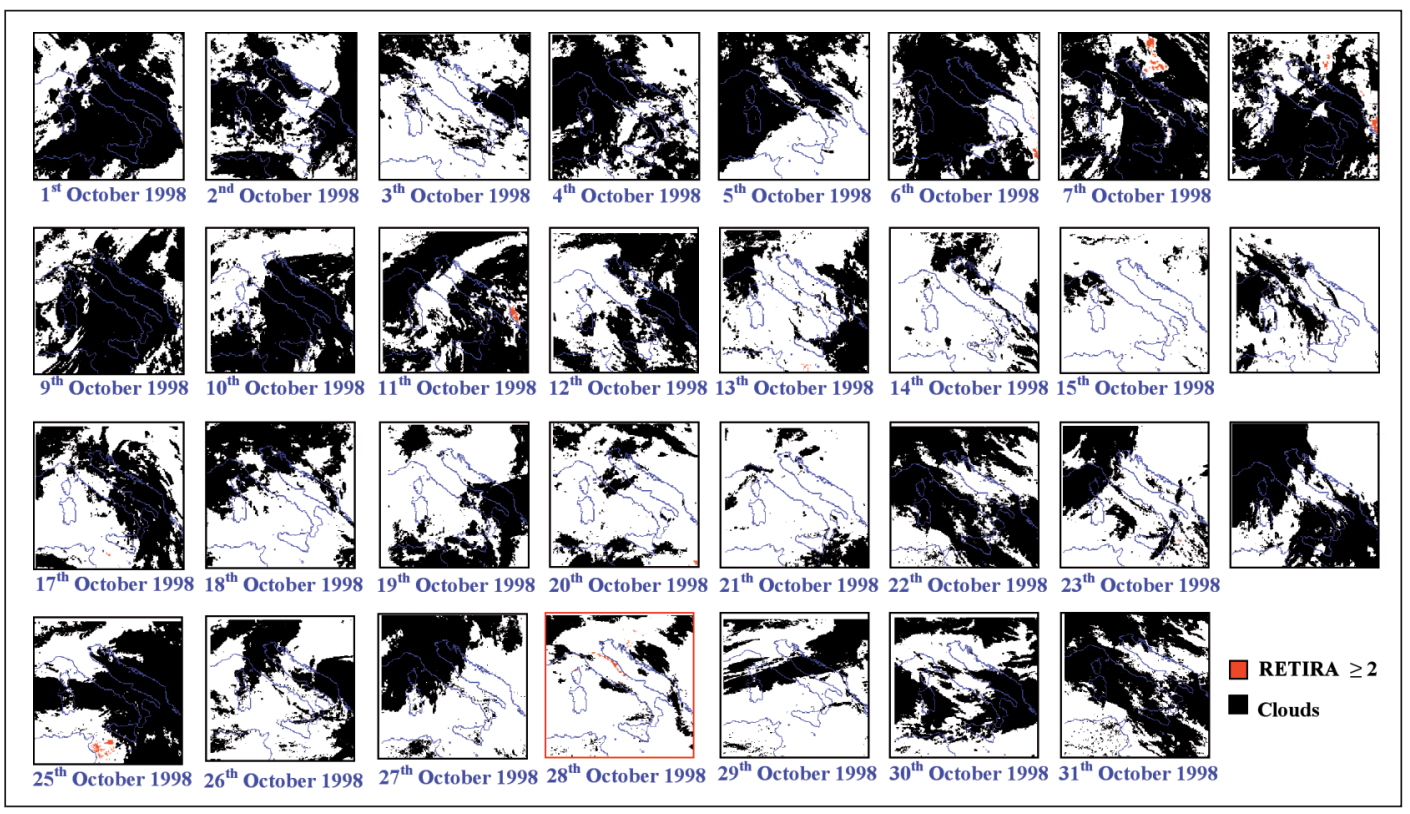

Fig. 5. Confutation: results of the RETIRA index computation on the investigated area; the red bordered image $\left(28^{\text {th }}\right.$ October) is the only one affected by anomalous pixels in the area of interest (see text).

Clouds have been detected by using the OCA approach (Cuomo et al., 2004) and are represented as black pixels. Overcast scenes are not shown as well as images (reported in fig. 3) evidently affected by navigation/co-location errors producing spurious TIR anomalies near the coast lines of the Sicily and Sardinia islands and southern regions. Examples and explanation of these and other known spurious effects have been given in Filizzola et al. (2004) and Aliano et al. (2008a). Here we just stress that the particular shape and the position along the sea-land boundary make such spurious thermal anomalies easy to recognize during the interpretation of the RETIRA computation results.

In spite of the extended cloudiness, fig. 2 identifies linear TIR anomalies (with $\otimes_{\Delta \mathrm{T}}(\boldsymbol{r}, t) \geq 2$ ), in the area of interest, located near the seismic epicentres and the main tectonic lineaments, some times overlapping them (see also fig. 4). They came out on $1^{\text {st }}$ October persisting until $4^{\text {th }}$ October (three seismic events, with
$4<\mathrm{M}_{\mathrm{W}}<5$, occurred on $2^{\text {nd }}, 3^{\text {th }}$ and $4^{\text {th }}$ October; another earthquake happened in the Ionian sea on $4^{\text {th }}$ October) to appear again on the $11^{\text {th }}$, the day before an earthquake of $\mathrm{M}_{\mathrm{b}}=5.1$ and three days before the main shock (see fig. 2). Recurrent TIR anomalies can also be observed (since October $1^{\text {st }}$ until October $23^{\text {rd }}$ ) in the area overlapping Western Alps where an earthquake of $\mathrm{M}_{1}=4.8$ occurred on October $31^{\text {st }}$.

Thermal anomalies over the Tyrrhenian region (far from epicentre area and tectonic structures) are probably related to night-time cloud passages (see Aliano et al., 2008a for details), even if the presence over the area of light greenhouse gases (i.e. methane), which spread broadly, cannot be excluded.

In this last hypothesis, such TIR anomalies could be in some way connected to the UmbriaMarche seismic activity. For an explanation of the different thermal anomaly shape depending on the relative density of the emitted gas, see Aliano et al., 2008b. 
Even if such analysis does not relate for sure (nor exclude) observed thermal anomalies to earthquakes, it suggests at least the crucial role played by a space-time persistence test to select TIR anomalies candidate to be associated with impending earthquakes.

In general, the relation between TIR anomalies appearance and earthquake magnitude (investigated for the same geologic setting) does not seem in contrast with the indications from the study performed by Corrado et al. (2005) on low-medium earthquakes $\left(4<\mathrm{M}_{b}<5.5\right)$ that occurred in Greece and Turkey: the observation of TIR anomalies at a $\mathrm{S} / \mathrm{N}$ level greater than 2 even in the presence of medium-low intensity earthquakes seem to suggest there is no direct relation between TIR anomaly intensity and earthquake magnitude.

\section{Confutation}

As far as the confutation is concerned, tests have been carried out considering the October, 1998 , to verify the absence of TIR anomalies in a relatively seismically unperturbed period. In fact, as it is reported by IRIS $\left({ }^{6}\right), 1998$ is the only one year between the 1992 and 2000 without earthquakes with $M_{b} \geq 4$ over the Italian area during the month of October.

The same analysis performed in the validation phase was used in this confutation step to identify anomalous (RETIRA index $\geq 2$ ) TIR space-time patterns. Figure 5 shows the results of the confutation analysis. Even by comparison with fig. 2 it is quite evident how rare the appearance of TIR anomalies is in this case. Moreover (and despite the frequent presence of clouds) it is quite evident that only spatially isolated and/or not time persistent (disappearing just in one day, as for October $28^{\text {st }}$ ) TIR anomalies were detected in the area of interest during October 1998.

${ }^{6}$ ) Incorporated Research Institutions for Seismology, seismic catalogue available at the WEB site http://www.iris.washington.edu

\section{Conclusions}

In this work, the RST approach has been applied for the first time to part of a seismic sequence. Nine years of Meteosat TIR observations have been analyzed to characterize the TIR signal behaviour in the absence of significant seismic activity. Earthquakes of different magnitude that occurred during October 1997 have been considered as a test case for validation purposes, while a relatively unperturbed period (no earthquakes with $\mathrm{M}_{\mathrm{b}} \geq 4$ ) has been analyzed in the confutation phase.

Despite the cloud coverage affecting both validation and confutation phases (increasing observational noise and reducing possibility to appreciate the space-time evolution of thermal pattern), we can conclude that:

- TIR anomalies with RETIRA $\geq 2$ are visible in some space-time correlation with the earthquake epicentres (some times overlapping the main tectonic lineaments)

- no similar significant (in terms of relative intensity and space-time persistence) TIR anomalies were detected during less seismically perturbed periods

- the study, performed on a sequence of seismic events closed in space-time to reduce possible site effects related to the local geo-tectonic setting, seems to confirm the possibility of observing TIR anomalies even in the presence of low (M 4) magnitude events.

On the whole, the present results, together with those achieved in previous works by the same authors, confirm the importance of timespace persistence in selecting a meaningful TIR anomalous pattern. However, our analysis does not relate for sure (nor exclude) observed thermal anomalies to impending earthquakes!

Problems still remain in interpreting thermal signals in a seismo-genetic region: understanding whether or not the observed anomalous TIR signals are in statistically significant relation with time and place of incoming earthquakes or are instead related to other natural phenomena. However this and previous findings obtained by the same authors disclose the role that TIR anomaly space-time persistence and shape analyses can play to decide if or not 
they could be related to seismic activity.

On the other hand, if the presence of clouds limits the applicability of such space-time persistence test on TIR anomalies, the use of MicroWave (MW) sensors could help to overcome such limitations. In fact, this kind of electromagnetic radiation, by penetrating (not raining) clouds, allows us to observe Earth's surface in any weather conditions. And even if passive MW sensors operate with a spatial resolution (10-50 km nadir view), which is much lower than the one (1-5 km) achievable by TIR sensors, it remains largely sufficient to monitor thermal anomalies we observed always at a wider scale around the epicentre zone.

\section{Acknowledgments}

This exploration was performed in the framework of STREGEOS (STress RElated GEohazards in South-Caucasus) Project funded by EU (Contract No 9310) in the framework of INTAS Programme.

\section{REFERENCES}

Aliano, C., R. Corrado, C. Filizzola, N. Pergola and V. TRAMUTOLI (2007): Robust satellite techniques (RST) for seismically active areas monitoring: the case of $21 \mathrm{st}$ May, 2003 Boumerdes/Thenia (Algeria) earthquake, Multitemp 2007, 18th - 20th July 2007, Louven, Belgium, doi 10.1109/MULTITEMP.2007. 4293042.

Aliano, C., R. Corrado, C. Filizzola, N. Pergola and V. Tramutoli (2008a): Robust TIR Satellite Techniques for monitoring earthquake active regions: limits, main achievements and perspectives, Annals of Geophysics, 51 (1), 303.

Aliano, C., R. Corrado, C. Filizzola, N. Pergola and V. TrAmutoli (2008b): Robust Satellite Techniques for monitoring TIR anomalies in earthquake prone areas in Proceedings of the 2008 IEEE GOLD Remote Sensing Conference, Frascati, Italy, 22-23 May 2008 (in press).

Corrado, R., R. Caputo, C. Filizzola, N. Pergola and C. Pietrapertosa, V. Tramutoli (2005): Seismically active areas monitoring by robust TIR satellite techniques: a sensitivity analysis on low magnitude earthquakes occurred in Greece and Turkey since 1995, Natural Hazards and Earth System Sciences, 5, 101-108.

Cuomo, V., C. Filizzola, N. Pergola, C. Pietrapertosa and V. TRAmutoli (2004): A self-sufficient approach for GERB cloudy radiance detection, Atmospheric Research, 72, (1-4), 39-56.

Di Bello, G., C. Filizzola, T. Lacava, F. Marchese, N. Pergola, C. Pietrapertosa, S. Piscitelli, I. Scaffidi and V. Tramutoli (2004): Robust Satellite Techniques for Volcanic and Seismic Hazards Monitoring, Annals of Geophysics, 47 (1), 49-64.

Filizzola, C., N. Pergola, C. Pietrapertosa and V. TraMUTOLI (2004): Robust satellite techniques for seismically active areas monitoring: a sensitivity analysis on September 7th 1999 Athens's earthquake, Physics and Chemistry of the Earth, 29, 517-527.

FREUND, F. (2002): Charge generation and propagation in rocks, J. Geodynamics, 33, 545-572.

GELLER R.J. (1997): Earthquake prediction: a critical review, Geophys. J. Int., 131, 425-450.

Genzano, N., C. Aliano, C. Filizzola, N. Pergola and V. TRAMUTOLI (2007): A robust satellite technique for monitoring seismically active areas: the case of Bhuj-Gujarat earthquake, Tectonophysics, 431, 197210.

Gorny, V.I., A.G. SAlman, A.A. Tronin et al. (1988): The Earth's outgoing IR radiation as an indicator of seismic activity, Proc. Acad.Sci. USSR, 301, 67- 69.

IRIS (Incorporated Research Institutions for Seismology), link to http://www.iris.washimgton.edu NEIC (National Earthquake Information Centre, link to: http://neic.usgs.gov/neis/epic/epic_global.html]

Ouzounov, D., N. Bryant, T. Logan, S. Pulinets and P. TAYLOR (2006): Satellite thermal IR phenomena associated with some of the major earthquakes, 1999-2003 Physics and Chemistry of the Earth, 31 (4-9), 154-163.

Ouzounov, D., D. Liu, K. Chunli, G. Cervone, M. KAFATOS and P. TAYLOR (2007): Outgoing long wave radiation variability from IR satellite data prior to major earthquakes, Tectonophysics, 431 (1-4), 211-220.

Pietrapertosa, C., N. Pergola, V. Lanorte and V. TraMUTOLI (2001): Self Adaptive Algorithms for Change Detection: OCA (the One-channel Cloud-detection Approach) an adjustable method for cloudy and clear radiances detection, in Technical Proceedings of the Eleventh International (A)TOVS Study Conference (ITSC-XI), Budapest, 20-26 September 2000, edited by J.F. Le MARSHALL and J.D.JASPER, (Bureau of Meteorology Research Centre), Melbourne, 281-291.

Pulinets S., Ouzounov, D., Ciraolo et al. (2006a): Thermal, atmospheric and ionospheric anomalies around the time of the Colima M7.8 earthquake of 21 January 2003, Annals of Geophysic, 24, 835-849.

Pulinets, S.A., D. Ouzounov, A.V. Karelin, K.A. BoYARCHUK and L.A. POKHMELNYKH (2006b): The physical nature of thermal anomalies observed before strong earthquakes, Physics and Chemistry of the Earth, 31 (4-9), 143-153.

QianG, Z.-J., X.-D. XU and C.-G. Dian (1991): Thermal infrared anomaly precursor of impending earthquakes, Chinese Science Bulletin, 36 (4), 319-323.

QIANG, Z.-J. and C.-G. DiAn (1992): Satellite thermal infrared impending temperature increase precursor of Gonghe earthquake of magnitude 7.0, Qinghai Province, Geoscience, 6 (3), 297-300.

Qiang, Z.-J., X.-D. XU and C.-G. DiAn (1997): Thermal infrared anomaly precursor of impending earthquakes, Pure and Applied Geophysics, 149, 159-171.

SARAF, A.K. and S. Choudhury (2005a): Satellite detects surface thermal anomalies associated with the Algerian earthquakes of May 2003, International Journal of Re- 
mote Sensing, 26 (13), 2705-2713.

SARAF, A.K. and S. CHOUdHURY (2005b): NOAA-AVHRR detects thermal anomaly associated with the 26 January 2001 Bhuj earthquake, Gujarat, India, International Journal of Remote Sensing, 26 (6), 1065-1073.

Salman, A., W.G. Egan and A.A. TRONIN (1992): Infrared remote sensing of seismic disturbances, in Polarization and Remote Sensing, (SPIE, San Diego, CA), 208-218.

Tramutoli, V. (1998): Robust AVHRR Techniques (RAT) for Environmental Monitoring: theory and applications, in Earth Surface Remote Sensing II, edited by G. CECCHI and E. Zilioli, (SPIE 3496), 101-113.

Tramutoli, V, G. Di Bello, N. Pergola and S. Piscitelli (2001): Robust Satellite Techniques for Remote Sensing of Seismically Active Areas, Annali di Geofisica, 44 (2), 295-312.

Tramutoli, V. (2005): Robust Satellite Techniques (RST) for natural and environmental hazards monitoring and mitigation: ten years of successful applications, in ISP MSRS 2005 Conference Proceedings, (Beijing, China).
Tramutoli, V., V. Cuomo, C. Filizzola, N. Pergola and C. Pietrapertosa (2005): Assessing the potential of thermal infrared satellite surveys for monitoring seismically active areas: the case of Kocaeli (Izmit) earthquake, August 17, 1999, Remote Sensing of Environment, 96, 409-426.

Tramutoli, V. (2007): Robust Satellite Techniques (RST) for Natural and Environmental Hazards Monitoring and Mitigation: Theory and Applications, Proceedings of Multitemp 2007, doi: 10.1109/MULTITEMP.2007.4293057.

Tronin, A.A. (1996): Satellite thermal survey-a new tool for the study of seismoactive regions, in International Journal of Remote Sensing, 41 (8), 1439-1455.

TronIN, A.A. (2000): Thermal IR satellite sensor data application for earthquake research in China, International Journal of Remote Sensing, 16, 3169-3177.

Tronin, A.A., M. Hayakawa and O.A. Molchanov (2002): Thermal IR satellite data application for earthquake research in Japan and China, Journal of Geodynamics, 33 (4-5), 519-534. 